\title{
KALAKKI - Kalkkistabiloidun puhdistamolietteen tuotteistaminen lannoitteeksi
}

\author{
Heidi Jaukkuri ${ }^{1,3)}$, Heini Manninen ${ }^{2,3)}$, Kaisa Muurimäki ${ }^{3)}$, Sinikka Ripatti ${ }^{3)}$, Pirjo Suhonen ${ }^{3)}$, Vilho \\ Partanen ${ }^{4}$ \\ 1) heidijaukkuri@gmail.com \\ manninenheini@gmail.com \\ ${ }^{3)}$ Savonia-ammattikorkeakoulu, PL 72,74101 IISALMI,Etunimi.Sukunimi@savonia.fi \\ 4)Iisalmen Vesi, PL 10, 74101 IISALMI,Vilho.Partanen@iisalmi.fi
}

\section{Tiivistelmä}

Puhdistamoliete on jätevedenpuhdistamon lopputuote, jota saadaan jäte- ja teollisuusvesien puhdistuksessa. Puhdistamoliete hygienisoidaan lisäämällä siihen kalkkia (kallkistabilointi).

Työn tarkoituksena oli selvittää kokemuksia kalkkistabiloinnin käytöstä puhdistamolietteessä ulkomailla ja kotimaassa sekä siihen liittyvät säädökset. Näiden tietojen avulla laadittiin Iisalmen Vedelle tuoteseloste kalkkistabiloidusta jätevesilietteestä.

Työssä haastateltiin iisalmelaisia viljelijöitä, jotka ovat käyttäneet Iisalmen Veden puhdistamolietettä aikaisemmin, sekä koottiin muiden jätevedenpuhdistamoiden kokemuksia kalkkistabiloidusta puhdistamolietteestä. Lisäksi kartoitettiin Iisalmen Veden puhdistamolieteurakoitsijan kokemuksia. Kansainvälisiä kokemuksia puhdistamolietteen käytöstä ja vaikutuksesta maaperään kerättiin kansainvälisistä tutkimuksista.

Puhdistamoliete on orgaaninen lannoite, jonka kuiva-ainepitoisuus kalkkistabiloituna on $40 \%$. Puhdistamoliete parantaa maan rakennetta. Kalkkistabiloinnilla saadaan nostettua puhdistamolietteen pH:ta ja maahan sijoitettuna se nostaa myös maan pH-arvoa. Iisalmen Veden puhdistamoliete on hyvä fosforilannoite, koska se sisältää paljon fosforia $(17 \mathrm{~g} / \mathrm{kg} \mathrm{ka})$.

Puhdistamolietettä saa levittää viljalle, sokerijuurikkaalle ja öljykasveille sekä sellaisille kasveille, joita ei käytetä ihmisen ravinnoksi eikä eläinten rehuksi. Nurmelle sitä saa levittää, jos nurmi perustetaan suojaviljan kanssa. Perunaa, juureksia ja vihanneksia saa viljellä viiden vuoden päästä siitä, kun puhdistamolietettä on viimeksi levitetty. Viljelijä on ilmoitusvelvollinen puhdistamolietteen käytöstä EU-tukihaun yhteydessä.

Iisalmessa on noin kymmenen tilaa, jotka ovat vastaanottaneet Iisalmen Vuohiniemen jätevedenpuhdistamon lietettä pelloilleen. Haastateltaviksi tiloiksi valittiin kolme kasvinviljelytilaa, jotka ovat viime aikoina käyttäneet puhdistamolietettä. Yhdellä tilalla on kasvinviljelyn lisäksi pienimuotoista lihakarjankasvatusta. Yhdellä tilalla on peltoa 500 hehtaaria, toisella 200 hehtaaria ja kolmannella 30 hehtaaria. Suurimat tilat ovat käyttäneet puhdistamolietettä lannoitteena jo noin 30 vuoden ajan, mutta pienimmällä tilalla on vastaanotettu puhdistamolietettä vain kolmena vuonna. Suurin osa tilojen maalajeista on karkeita kivennäismaita, hiesua (30 \%) ja hietamoreenia (29\%). Seuraavaksi eniten on hiesusavea (16\%) ja hiuetta (11\%). Muina maalajeina on hienohieta, multamaa, karkeahieta ja hiuesavi. Lietteen käytön ansiosta viljelykasvien fosforilannoitustarve täyttyi ja jopa ylittyi. Typpitäydennystä sitä vastoin tarvittiin väkilannoitteilla. Alueen vähäisen teollisuuden vuoksi peltojen raskasmetallipitoisuudet eivät lisääntyneet

Tutkimusta kalkkistabiloidusta puhdistamolietteestä lannoitteena jatketaan Maa- ja elintarviketalouden tutkimuskeskuksessa Maaningalla.

Asiasanat: kalkki, stabilointi, puhdistamoliete, lannoitus 


\section{Johdanto}

Maaliskuussa 2007 voimaan astuneen maa- ja metsätalousministeriön (MMM) uuden lannoitevalmisteasetuksen (656/01/2007) mukaan kaikki lannoitetuotteet on käsiteltävä tyyppinimihyväksynnän saaneen menetelmän mukaisesti. Tämä lannoitevalmisteasetus vaikuttaa myös Iisalmen Veden toimintaan, jonka vuoksi Iisalmen Vesi käynnisti projektin puhdistamolietteen käsittelymenetelmän kehittämiseksi. Projektissa kehitetään puhdistamolietteen kalkkikäsittelyä ja varastointia vastaamaan uuden lainsäädännön vaatimuksia sekä kiinnitetään huomiota puhdistamolietteen hajuhaittoihin.

Kalkkistabiloitua puhdistamolietettä testataan Maa- ja elintarviketalouden tutkimuskeskuksen (MTT) Maaningan tutkimusasemalla neljän vuoden ajan. Tutkimusten tavoitteena on tuottaa käytännönläheistä tietoa viljelijöille kalkkistabiloidun puhdistamolietteen käytöstä lannoitteena. Tutkimuksessa verrataan kalkkistabiloitua puhdistamolietettä karjanlantaan ja väkilannoitteisiin.

Kalkkistabilointikokeilu on ensimmäisiä Suomessa. Muualla Euroopassa siitä on enemmän kokemusta maatalouskäytössä. Tämän työn tavoitteena oli selvittää suomalaisia ja ulkomaalaisia tutkimustuloksia sekä viljelijöiden kokemuksia puhdistamolietteen käytöstä maataloudessa. Näiden selvitysten perusteella on laadittu tuoteseloste, joka helpottaa kalkkistabiloidun puhdistamolietteen markkinointia paikallisille viljelijöille.

\section{Aineistot ja menetelmät}

Työhön kerättiin pohjatiedoksi puhdistamolietteen käyttöä maataloudessa koskeva lainsäädäntö. Suomalaisia kokemuksia kerättiin kolmelta iisalmelaiselta tilalta, iisalmelaiselta puhdistamolieteurakoitsijalta sekä kalkkistabilointia käyttäviltä jätevedenpuhdistamoilta. Viljelijöitä ja puhdistamolieteurakoitsijaa haastateltiin henkilökohtaisesti ja haastattelut nauhoitettiin. Nauhoitukset purettiin mahdollisimman nopeasti haastattelun jälkeen tekstimuotoon. Kaikkiaan Iisalmessa on noin kymmenen tilaa, jotka ovat 30 vuoden aikana käyttäneet puhdistamolietettä lannoitteena. Haastatteluun valittiin ne kolme tilaa, jotka olivat käyttäneet puhdistamolietettä viimeisen kolmen vuoden aikana. Koska haastateltavia viljelijöitä oli vähän, halusimme myös kuulla iisalmelaisen puhdistamolieteurakoitsijan mielipiteen puhdistamolietteestä lannoitteena.

Kalkkistabilointia käyttäviä jäteveden puhdistamoita etsittiin Suomen ympäristökeskuksesta saatavien tietojen avulla. Kyseisten selville saatujen jätevedenpuhdistamoiden edustajia haastateltiin joko puhelimitse tai sähköpostin välityksellä. Puhelimitse saadut tiedot kirjattiin heti puhelun yhteydessä ylös. Haastattelimme kalkkistabilointimenetelmää käyttäviä jätevedenpuhdistamoita, koska halusimme selvittää, kuinka paljon Suomessa käytetään kalkkistabiloitua puhdistamolietettä maatalouden lannoitteena ja millaisia kokemuksia heidän alueellaan on sen käytöstä.

Ulkomaalaisia kokemuksia kerättiin saatavilla olevista erilaisista tutkimuksista eri puolilta Eurooppaa sekä Pohjois-Amerikasta, Australiasta ja Iranista. Eurooppalaisia tutkimuksia puhdistamolietteestä oli saatavilla Itävallasta, Iso-Britanniasta, Kreikasta, Espanjasta sekä Norjasta. Tutkimukset käsittelivät fosforin saatavuutta ja ravinteiden käyttökelpoisuutta kasveille, raskasmetallien vaikutusta satoon varoajan jälkeen sekä puhdistamolietteen vaikutusta maan laatuun ja ravinnetasoon.

\section{Tulokset ja tulosten tarkastelu}

Puhdistamolietettä syntyy yhdyskuntien asuma- ja teollisuusjätevesien puhdistuksessa. Puhdistamoliete koostuu orgaanisesta aineksesta, fosforista, typestä ja hivenravinteista. Suomessa tuotetusta puhdistamolietteestä käytetään noin 10 \% lannoitteena maataloudessa. (Vihersaari, V. 2003; Kapuinen, P. 2008.)

Valtioneuvoston päätös puhdistamolietteen käytöstä maanviljelyksessä (282/1994) rajaa puhdistamolietteen käytön seuraaville kasveille: viljalle, sokerijuurikkaalle ja öljykasveille tai sellaisille kasveille, joita ei käytetä ihmisen ravinnoksi tai eläimen rehuksi. Puhdistamolietteen levitys nurmelle on sallittua, kun se perustetaan suojaviljan kanssa. Puhdistamolietteellä lannoitetun maan varoaika on viisi vuotta, jonka jälkeen perunan, juureksien ja vihannesten viljely on mahdollista. Viljelymaan $\mathrm{pH}: \mathrm{n}$ tulee olla yli 5,8 käytettäessä puhdistamolietettä. Kalkkistabiloidulle puhdistamolietteelle maan pHarvoksi riittää 5,5. Puhdistamolietteelle ja viljelymaan raskasmetallipitoisuuksille on asetettu sallitut raja-arvot. 
MMM on laatinut ohjeen puhdistamolietteenkäytöstä maataloudessa (2915/835/2005), jonka mukaan puhdistamoliete on käsiteltävä Elintarviketurvallisuusviraston (EVIRA) hyväksymällä menetelmällä ennen maatalouskäyttöä. Näitä menetelmiä ovat termofiilinen mädätys, kalkkistabilointi, kompostointi, terminen kuivaus ja kemikond-menetelmä. (N:o 282/1994; MMMELO 2915/835/2005.)

Kalkkistabiloinnissa puhdistamolietteeseen lisätään kalkkia joko puhdistamolietteen kuivauksen yhteydessä tai sen jälkeen. Kalkki aiheuttaa reaktion, jossa puhdistamolietteen pH ja lämpötila kohoavat. Kun pH-arvo on yli 12 vähintään kahden tunnin ajan, kalkkistabiloitu puhdistamoliete täyttää sille asetetut vaatimukset. Norjalaisen tutkimuksen mukaan puhdistamolietteellä lannoitetun maan $\mathrm{pH}-$ arvo nousee $0,5-1,5$ yksikköä.

Lisäksi kalkkistabiloitu puhdistamoliete sisältää noin $50 \%$ orgaanista ainesta, joka parantaa maan mururakennetta sekä edistää maan vedenpidätyskykyä. Se parantaa maan vesitaloutta, ilmanvaihtoa ja ravinteiden sitomiskykyä sekä vilkastuttaa pieneliötoimintaa. Puhdistamolietteen orgaanisen aineksen hajoaminen on hidasta, joten sen vaikutus maassa kestää useita vuosia. MTT:n Maaningan tutkimusasemalla tehtyjen Iisalmen Veden projektiin liittyvien ensimmäisen vuoden peltokoetutkimustulosten mukaan kalkkistabiloidulla puhdistamolietteellä lannoitettu maa on NPK -moniravinteen veroinen, kun sen yhteydessä käytetään lisäksi NK-ravinnetta. Puhdistamolietteen todettiin lisäävän viljan lakoa. (MMMELO 2915/835/2005; Kapuinen, P. 2008; Pakarinen, K. 2009; Grønsten. 2008.)

Itävaltalainen Seyhan ja turkkilainen Erdincler ovat tutkineet fosforin saatavuutta kalkkistabiloidussa puhdistamolietteessä. Heidän tutkimuksen mukaan kalkkistabiloidun puhdistamolietteen lisääminen maahan nosti satotasoa, mutta ei nostanut kasvin fosforin ottoa. Tutkijoiden mukaan kalkkistabiloidussa puhdistamolietteessä on saatavilla vähemmän liukoista fosforia kuin jätevesilietteessä. Lisäksi heidän mielestään kalkkistabilointi tekee maasta kokkareisen ja heikentää fosforin saantia. Tutkijat epäilevät myös kalkin mukana tulevan kalsiumin heikentävän fosforin liukenemista. Isobritannialaisen tutkimuksen mukaan puhdistamolietteen fosforin määrä on riippuvainen alumiinin ja raudan määrästä. Norjalaisessa tutkimuksessa on todettu vesiliukoisen fosforin määrän nousevan, kun puhdistamolietteen rautapitoisuus on matala. Isobritannialaisen tutkimuksen mukaan on arvioitu, että kokonaisfosforista noin $50 \%$ on kasveille käyttökelpoisessa muodossa. (Seyhan \& Erdincler. 2003; Hogan ym. 2001; Grønsten. 2008.)

Pohjois-Amerikassa tehdyn tutkimuksen mukaan kalkkistabilointiin tarvitaan $30 \mathrm{~g}$ kalkkia puhdistamolietekiloa kohti hapettomissa olosuhteissa 20-22 asteen lämpötilassa, jotta puhdistamolietteestä saadaan A-luokkaista. A-luokan vaatimustaso täyttyy, kun puhdistamolietteessä ei havaita taudinaiheuttajia. Iranissa tehdyssä tutkimuksessa on selvitetty, että pH-arvon nousu yli 11 vuorokauden ajaksi, on riittävä A-luokan puhdistamolietteen saavuttamiseksi. Kreikkalaisen tutkimuksessa on selvitetty, että kalkkia tarvitaan 6-10\% puhdistamolietteen kuiva-ainepitoisuudesta, jotta $\mathrm{pH}$ nousee 12. (AbuOrf ym. 2004; Bina ym. 2004; Andreadakis. 1999.)

Itävallassa on viljelijöiden kokemusten perusteella todettu kalkkistabiloidun puhdistamolietteen ja karjanlannan sekoituksen nostavan fosforin ravintoarvoa, maan $\mathrm{pH}$-arvoa sekä kaliumin ja magnesiumin arvoja. Maan pH on noussut 5,1-6,2:sta 5,5-6,7:ään. Monilla englantilaisilla tiloilla on käytetty puhdistamolietettä jo pitkään ja huomattu sen tekevän maasta viljavampaa. Sen käyttö on myös vähentänyt tuulieroosiota ja pienentänyt lannoitekustannuksia. Satotasojen on jopa huomattu nousevan verrattaessa pelkästään karjanlannalla lannoitettuihin maihin. Myös koillisespanjalaisilla tiloilla on huomattu lannoitekustannusten pienenevän, kun on käytetty puhdistamolietettä lannoitteena. Satotasot eivät kuitenkaan ole nousseet. Pitkäaikaisesta käytöstä huolimatta ei ole havaittu raskasmetallipitoisuuksien merkittäviä nousua. Raskasmetallien vaikutuksesta satoon viiden vuoden varoajan jälkeen on tehty tutkimusta Iso-Britanniassa. Tämän tutkimuksen mukaan joidenkin raskasmetallipitoisuuksien arvot $(\mathrm{Cd}, \mathrm{Ni}, \mathrm{Cu}, \mathrm{Zn})$ nousivat viljeltäessä perunaa, vehnää, kaalia ja punajuurta. Samassa tutkimuksessa todettiin, että vaikka suurilla puhdistamolietelisäyksillä maan raskasmetallipitoisuudet nousivat lain sallimiin maksimipitoisuuksiin, viljelykasveissa ei havaittu liian suuria raskasmetallipitoisuuksia. Tutkimuksessa tutkittiin myös satotasojen nousua ja todettiin, että $26 \%$ tutkimuksessa olleista tiloista satotasot nousivat ja $60 \%$ ei satotasoissa tapahtunut muutoksia. (Evans. 2004; FAO.)

Iisalmessa on noin kymmenen tilaa, jotka ovat vastaanottaneet Iisalmen Vuohiniemen jätevedenpuhdistamon lietettä pelloilleen. Haastateltaviksi tiloiksi valittiin kolme tilaa, jotka ovat viime aikoina käyttäneet puhdistamolietettä. Kaikki haastatellut tilat ovat kasvinviljelytiloja. Yhdellä tilalla on kasvinviljelyn lisäksi pienimuotoista lihakarjankasvatusta. Yhdellä tilalla on peltoa 500 hehtaaria, toisella 200 hehtaaria ja kolmannella 30 hehtaaria. Kokoluokaltaan isommat tilat ovat käyttäneet puh- 
distamolietettä lannoitteena jo noin 30 vuoden ajan, mutta pienimmällä tilalla on vastaanotettu puhdistamolietettä vain kolmena vuonna. Suurin osa tilojen maalajeista on karkeita kivennäismaita, hiesua (30\%) ja hietamoreenia (29\%). Seuraavaksi eniten on hiesusavea (16\%) ja hiuetta (11\%). Muina maalajeina on hienohieta, multamaa, karkeahieta ja hiuesavi. Lietteen käytön ansiosta viljelykasvien fosforilannoitustarve täyttyi ja jopa ylittyi. Typpitäydennystä sitä vastoin tarvittiin väkilannoitteilla. Alueen vähäisen teollisuuden vuoksi peltojen raskasmetallipitoisuudet eivät lisääntyneet

Iisalmelaisten puhdistamolietettä käyttävien tilojen kokemusten mukaan puhdistamoliete parantaa maan multavuutta ja vilkastuttaa pieneliötoimintaa parantaen maan vesitaloutta. Satotason muutosta iisalmelaiset viljelijät eivät uskalla perustella ainoastaan puhdistamolietteen käyttöön. Puhdistamolietteen vähäisen typpipitoisuuden vuoksi, viljelijät ovat lannoittaneet peltojaan puhdistamolietteen lisäksi myös väkilannoitteilla. Iisalmelaisen puhdistamolieteurakoitsijan mukaan etenkin savimailla on voinut havaita muutoksia maaperässä. Hän kertoi savimaiden olleen aiemmin kosteita ja helposti jankkoutuvia, mutta puhdistamolietteen käytön jälkeen niiden vedenläpäisykyky on parantunut. Urakoitsijan mukaan ihmisten reaktiot puhdistamolietteen käytöstä ovat kohdistuneet siitä aiheutuvaan hajuhaittaan. Teorian mukaan hajuhaitan pitäisi pienentyä kalkkistabiloinnilla. Haastateltujen kalkkistabilointia käyttävien jätevedenpuhdistamoiden edustajien mukaan hajuhaitat ovat vähentyneet siirryttäessä kalkkistabilointiin. Tosin osalla jätevedenpuhdistamoista kalkkistabilointi oli ollut käytössä jo parin kymmenen vuoden ajan, joten voidaan olettaa, että kalkkistabilointimenetelmä ei täysin vastaa nykyistä termiä. Yhden jätevedenpuhdistamon mukaan hajuhaitat ovat merkittäviä kalkinlisäysvaiheessa, kun pH ja samalla puhdistamolietteen lämpötila nousevat. Tällöin tapahtuu ammoniakin haihtumista, josta syntyy hajuhaittaa. Jätevedenpuhdistamoiden edustajat kertoivat, että paikallisesti valituksia ei ole tullut paljoa, etenkin jos puhdistamoliete on mullattu mahdollisimman pian.

Puhdistamolietteen on täytettävä lannoitelaissa määrätyt laatu- ja hygieniavaatimukset. Jokaisen puhdistamolietteen tuote-erän yhteydessä on toimitettava viljelijälle tuoteseloste. Tuoteselosteessa tulee ilmoittaa kuiva-ainepitoisuus, orgaanisen aineksen määrä, happamuus, johtokyky, kokonaistyppi, kokonaisfosfori ja kokonaiskalium. Lisäksi liitteenä tulee olla analyysitodistus, jossa todetaan kadmiumin, kromin, kuparin, nikkelin, lyijyn, sinkin, elohopean ja arseenin pitoisuudet ( $\mathrm{mg} / \mathrm{kg}$ kuivaainetta). Analyysitodistuksessa tulee myös todistaa puhdistamolietteen alittavan salmonellan ja Escherischia colin sallitun määrän. (MMMELO 2915/835/2005.)

\section{Puhdistamolietteen tuoteseloste}

Iisalmen Vedelle tehtiin kaksi erilaista tuoteselostetta, joista toinen on A4-kokoa ja toinen on A4koosta kolmeen osaan taiteltu haitarimalli. Haitarimalli tehtiin sen vuoksi, että se mahtuu helpommin kulkemaan viljelijöiden mukana peltotöissä. Käytännönläheisyyden lisäksi haitarimallista haluttiin tehdä silmää miellyttävä. Taiteltavassa mallissa on etu- ja takapuoli, ja siihen on lisätty kuvia ja väriä. A4-koon mallista on jätetty kuvat pois, sillä sen tarkoitus on sisältää informatiivista tekstiä. Taiteltavaan tuoteselosteeseen on tehty taulukko, jossa kerrotaan puhdistamolietteen analyysitulokset ravinteiden ja haitallisten raskasmetallien osalta sekä ilmoitetaan raja-arvot, joita raskasmetallipitoisuudet eivät saa ylittää. Lisäksi tuoteselosteessa kerrotaan puhdistamolietteen valmistuksesta ja valmistajasta sekä ohjeistetaan viljelijää puhdistamolietteen käytöstä, käyttömääristä, levityksestä sekä tilauksesta ja saatavuudesta. Tuoteselosteessa on myös maininta viljelijän velvollisuudesta ilmoittaa puhdistamolietteen käytöstä lannoitteena päätukihaun yhteydessä. Ilmoitus tehdään merkitsemällä rastitukihakulomakkeen puhdistamolietteen käyttöä koskevaan kohtaan 101A.

Iisalmen Veden kalkkistabiloitu puhdistamoliete valmistetaan, lisäämällä $10 \%$ kalkkia puhdistamolietteen kuiva-aineesta. Valmis kalkkistabiloitu puhdistamoliete joko varastoidaan Peltomäen jätekeskuksessa sijaitsevaan katettuun varastoon tai levitetään suoraan paikallisten viljelijöiden pelloille. Kalkkistabiloidun puhdistamolietteen fosforipitoisuus Iisalmessa on $17 \mathrm{~g} / \mathrm{kg} \mathrm{ka}$, joten se on hyvä fosforilannoite. Lannoitteen käyttömäärää rajoittaa nitraattidirektiivi sekä pellon ja puhdistamolietteen raskasmetallipitoisuudet. Iisalmen Veden puhdistamolietteen raskasmetallipitoisuudet alittavat Valtioneuvoston päätöksessä 282 määritetyt raskasmetallien sallitut enimmäispitoisuudet. Iisalmen Veden puhdistamolietteen vastaanotto on tällä hetkellä ilmaista viljelijälle ja levitys tapahtuu jätevesilieteurakoitsijan toimesta. (Sipilä. 2008; N:o 282/1994.) Kuvissa 1 ja 2 on esitetty Iisalmen Vedelle hahmotellun taiteltavan tuoteselosteen etusivu (kuva 1) ja takasivu (kuva 2).

Tuoteselosteiden luettavuuden vuoksi, niihin laitettiin vain pakolliset puhdistamolietteen käyttöä ohjeistavat ja lain vaatimat tiedot. Tarkoituksena oli myös tuoda viljelijöiden tietoisuuteen kalkki- 
stabiloidun puhdistamolietteen tutkimustuloksia ja kokemuksia sen käytöstä. Aikaisemmin esiteltyjen kotimaisten ja ulkomaisten tutkimusten tuloksia ja haastattelujen pohjalta saatuja tietoja on kerätty viljelijöiden nähtäväksi lyhyesti tiedotteen muotoon. Tiedote tulee olemaan nähtävillä Iisalmen Veden kotisivuilla.

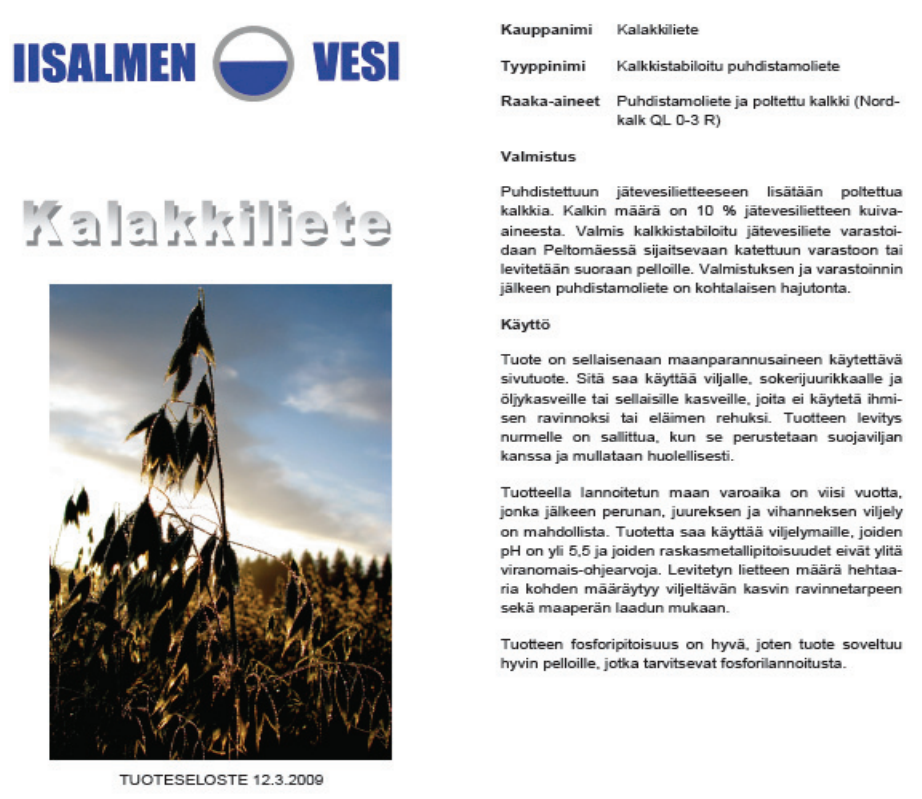

KUVA 1. Taiteltavan tuoteselosteen etusivu

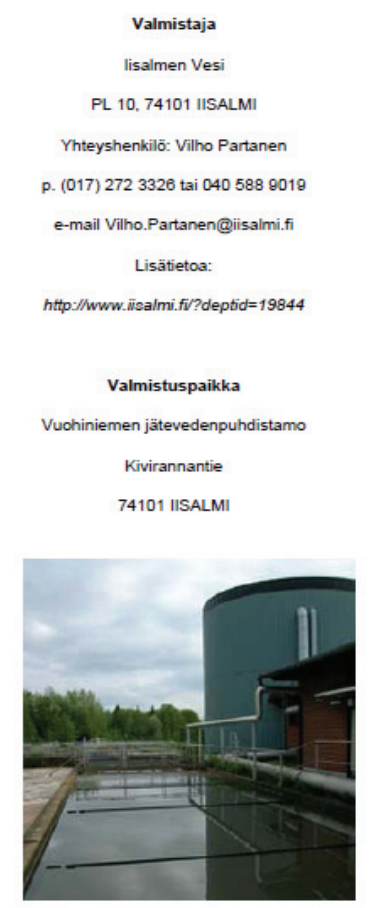

\begin{tabular}{|c|c|c|}
\hline \multicolumn{3}{|l|}{ Pääravinteet } \\
\hline Kokonaispitoisuus & Kalakkiliete & $\begin{array}{l}\text { Raja- } \\
\text { arvot }\end{array}$ \\
\hline Typpi (N) & 40 & \\
\hline Fosfori (P) & 17 & \\
\hline Kalium (K) & 2,8 & \\
\hline \multicolumn{3}{|l|}{ Liukoiset pitoisuudet } \\
\hline Typpi (N) & 12 & \\
\hline \multicolumn{3}{|l|}{ Fosfori (P) } \\
\hline Haitallisten raskametallit & $\mathrm{mg} / \mathrm{kg} \mathrm{ka}$ & $\mathrm{mg} / \mathrm{kg} \mathrm{ka}$ \\
\hline Kupari (Cu) & 222 & 600 \\
\hline Sinkki (Zn) & 502 & 1500 \\
\hline Kadmium (Cd) & 0,21 & 3 \\
\hline Kromi $(\mathrm{Cr})$ & 15,2 & 300 \\
\hline Elohopea $(\mathrm{Hg})$ & 0,23 & 2 \\
\hline Nikkeli (Ni) & 31,5 & 100 \\
\hline Lyijy $(\mathrm{Pb})$ & 12,2 & 150 \\
\hline \multicolumn{3}{|l|}{ Tilavuuspaino } \\
\hline Kosteus $\left(\mathrm{H}_{2} \mathrm{O}\right)$ & $75-80 \%$ & \\
\hline \multicolumn{3}{|c|}{ Orgaaninen aines $50 \%$ kuiva-aineesta } \\
\hline \multicolumn{3}{|l|}{ Johtokyky } \\
\hline $\mathrm{pH} \quad 12,4$ & & \\
\hline
\end{tabular}

IISALMEN $\bigcirc$ VESI

Nordkalk

Kuva 2. Taiteltavan tuoteselosteen takasivu 


\section{Johtopäätökset}

Kalkkistabilointimenetelmä on hyvä vaihtoehto jätevedenpuhdistamoille, joilla on mahdollisuus toimittaa tuotettu puhdistamoliete alueen viljelijöiden pelloille. Kalkkia tarvitaan 6-10\% puhdistamolietteen kuiva-ainepitoisuudesta, jotta puhdistamoliete on hygieniavaatimukset täyttävää. Laatuvaatimuksina on riittävän alhainen raskasmetallipitoisuus sekä riittävä puhtaus salmonellasta ja Escherichia colista. Pellon ja puhdistamolietteen raskasmetallipitoisuus rajoittaa nitraattidirektiivin lisäksi puhdistamolietteen käyttömäärää. Kansainvälisten kokemusten mukaan puhdistamolietteen käyttö pienentää lannoitekustannuksia. Tutkimusten mukaan kalkkistabiloitu puhdistamoliete nostaa maan $\mathrm{pH}$-arvoa, parantaa maan rakennetta, vähentää tuulieroosiota ja on hyvä fosforilannoite.

Iisalmen Vedelle laadittu tuoteseloste sisältää puhdistamolietettä koskevan lain vaatimat tiedot. Analyysitulosten osalta se on helppo päivittää vastaamaan jokaista tuotettua tuote-erää. Tuoteseloste toimii viljelijän apuna ohjeistamassa häntä puhdistamolietteen lainmukaisesta käytöstä. Lisätietoa kalkkistabiloidusta puhdistamolietteestä lannoitteena viljelijät saavat Iisalmen Vedelle laaditusta tiedotteesta sekä Kalakki - Kalkkistabiloidun puhdistamolietteen tuotteistaminen lannoitteeksi -opinnäytetyöstä, joka on saatavissa ammattikorkeakoulujen verkkokirjastosta: http://www.theseus.fi.

\section{Kirjallisuus}

Abu-Orf ym. 2004. Production of class A biosolids with anoxic low dose alkaline treatment and odor management. Water Science and Technology vol 49, 131-138. IWA Publishing.

Andreadakis, A.D. 1999. Treatment and disinfection of sludge using quicklime. Waste management \& research. Kreikka. 31-37.

Evans, T. 2004. Layman's Guide to the Use of Sludge in Acriculture.

Hogan, McHugh, Morton. 2001. Phosphorus availability for beneficial use in biosolids products. Environmental Technology vol. 22, 1347-1353.

Seyhan, Erdincler. 2003. Effect of lime stabilisation of enhanced biological phosphorus removal sludges on the phosphorus availability to plants. Water Science and Technology vol 48, 155-162. IWA Publishing.

Sipilä, A. 2008. Testausseloste. Kuopio. 22.7.2008. Savo-Karjalan ympäristötutkimus Oy, elintarvikeyksikkö.

Bina, Movahedian, Kord. 2004. The effect of lime stabilization on the microbiological quality of sewage sludge. [Viitattu 28.10.2008]. Saatavissa:

http://journals.tums.ac.ir/upload_files/pdf/489.pdf

FAO. Agricultural use of sewage sludge. [Viitattu 7.4.2008]. Saatavissa:

http://www.fao.org/docrep/T0551E/t0551e08.htm

Kapuinen, P. 2008. Lietteen hyötykäyttö maataloudessa. [Viitattu 12.11.2008].

Saatavissa: http://www.vvy.fi/files/54/kapuinen_petri.pdf

Maa- ja Metsätalousministeriö. 2005. Maa- ja metsätalousministeriön ja Kasvintuotannon

tarkastuskeskuksen ohje maataloudessa käytettävälle puhdistamolietteelle

2915/835/2005. [Viitattu 2.4.2008]. Saatavissa:

http://74.125.77.132/search?q=cache:IN8RqTSAmjsJ:www.kunnat.net/attachment.asp \%3Fpath\%3D1\%3B29\%3B356\%3B24897\%3B51777\%3B86783+2915/835/2005\&hl

$=\mathrm{fi} \& \mathrm{ct}=\mathrm{clnk} \& \mathrm{~cd}=1 \& \mathrm{gl}=\mathrm{fi}$

Mikola, A., Rautiainen, J. 2008. Vuohiniemen jätevedenpuhdistamolietteen kalkkistabilointiprosessin kehittäminen.

Pakarinen, K. 2009. KALAKKI-projektista [Sähköpostiviesti]. kirsi.pakarinen@mtt.fi. 23.2.2009. [Viitattu 27.2.2009].

Puhdistamolietteen käytöstä maataloudessa (N:o 282/1994). Finlex. [Viitattu

2.4.2008]. Saatavissa: http://www.finlex.fi/fi/laki/alkup/1994/19940282

Vihersaari,V. 2003. Puhdistamoliete- fosforilannoitteena. Varsinais-Suomen Agenda 21. [Viitattu8.10.2008]. Saatavissa: http://www.vsagendatoimisto.fi/vesiensuojelu/liete/Puhdistamolietefosforilannoitteena. pdf 